\title{
Flagger Struck by Motorist and Killed
}

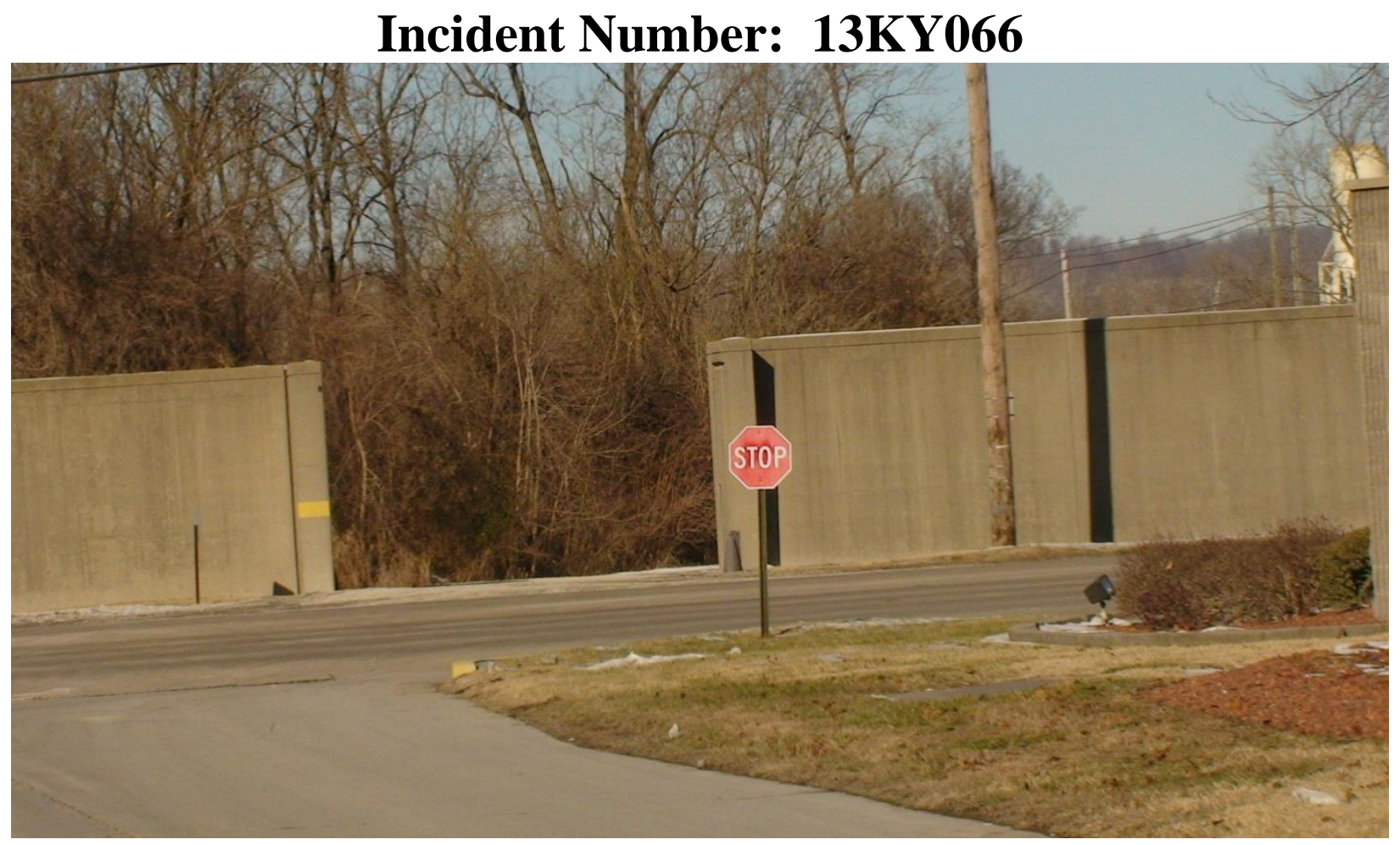

Photograph courtesy of KY OSHA

Kentucky Fatality Assessment and Control Evaluation Program Kentucky Injury Prevention and Research Center 333 Waller Avenue

Suite 242

Lexington, Kentucky 40504

Phone: 859-323-2981

Fax: 859-257-3909

www.kiprc.uky.edu

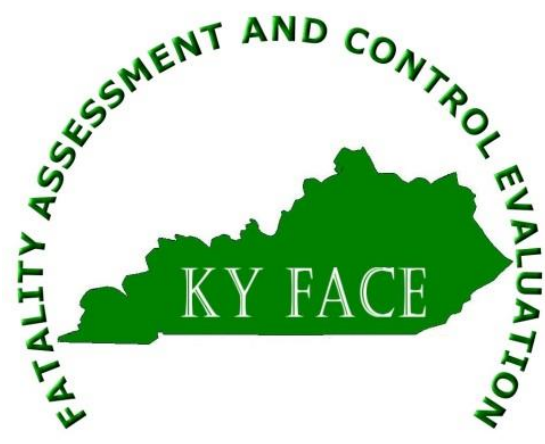




\section{Kentucky Fatality Assessment and Control Evaluation (FACE) Program \\ Incident Number: 13KY066 \\ Release Date: December 8, 2014 \\ Subject: Flagger Struck by Motorist and Killed}

\section{$\underline{\text { Introduction }}$}

On December 12, 2013 at 7:32 pm, a 59-year-old derrick operator was directing traffic to stop on a major 5 lane north-south highway, to allow a 40-ton truck and a large front loader to cross the unlit roadway. The victim was wearing a dark gray jacket with orange reflective stripes on each sleeve, above each front pocket and across the upper half of the back, a white hard hat and dark trousers. He was holding a small flashlight and a non-reflective stop sign. As he was standing in the roadway, he was struck by a 2002 red Chevrolet S10 pickup truck in the right northbound lane, traveling at $50 \mathrm{mph}$. The driver of the pickup truck stated he did not see the flagger. According to the driver's operator license, the driver was required to wear corrective lenses. The driver was not wearing the corrective lenses at the time of the collision and informed the officer at the scene that he had a cataract affecting his right eye. Witnesses called Emergency Medical Services (EMS) and administered CPR. The EMS arrived and declared the victim dead at the scene.

The victim did not have experience as a flagger and was not wearing highly reflective clothing as required by the Manual on Uniform Traffic Control Devices (MUTCD) code, which requires a class 3 high visibility reflective safety vest and a reflective stop sign for those flagging at night.

To prevent future occurrences of similar incidents, the following recommendations have been made:

Recommendation No. 1: Employers should implement and enforce traffic control-related worker safety training in addition to properly setting up an MUTCD.

Recommendation No. 2: Employers should provide proper MUTCD reflective clothing when employees are required to perform traffic control activities.

Recommendation No. 3: Employers should avoid assigning traffic control activities after dark.

Recommendation No.4: When corrective lenses are prescribed and an operator's license is restricted to driving with corrective lenses, motorists must wear the corrective lenses while driving.

\section{$\underline{\text { Employer }}$}

The employer was a surface cement facility that operates two 12-hour shifts per day, seven days a week, with 149 employees. Material is brought in by barges, offloaded with excavators and 
transported by conveyors, where it is then pulverized, heated and processed to produce cement. Finished product is stored in silos and transported to customers by bulk trucks, barges, and railway.

\section{Written Safety Programs and Training}

The cement facility's training and safety programs were reviewed and found to be in compliance with MSHA's safety and training requirements as well as OSHA's requirements, however they were lacking adequate flagger safety training and appropriate PPE for night time flagging.

\section{Victim}

The victim was a 59-year-old white male who had been employed with the company for 32 years. His occupation was derrick operator. The victim was a high school graduate and was working second shift, 6:00 p.m. to 6:00 a.m. He was a father of three and a grandfather of six.

\section{Incident Scene}

The scene was located in front of an entrance to a cement factory. The roadway was straight and consisted of 5 lanes running north and south bound, two lanes running north with two lanes running south and a middle turn lane. The victim was in the right lane of the highway attempting to stop northbound lanes. The speed limit for this highway was $55 \mathrm{mph}$. The vehicle travel lanes for the roadway were divided by broken white lines. A solid white line was present for the right side of the roadway in each direction. A yellow solid/broken line was present to mark the median's lane dimension. Emergency shoulders were present in both directions. See photo \#5. The second flagger was on the southbound side.

\section{Weather}

Tuesday December 10, 2013 was a dark cloudy cold night with temperatures ranging from 22 to 32 degrees Fahrenheit, with light snow on the ground.

\section{Investigation}

The Kentucky Fatality Assessment and Control Evaluation Program was notified by the Kentucky Labor Cabinet of an occupational fatality involving a labor worker. An investigation into the fatality was opened and conducted.

The fatality occurred on a 5 lane highway in front of the entrance to the cement company. The second shift employees reported to work at 6:00 p.m. The shift notes directed employees to lay down rock in an area where trailers had been parked. This area was wet and muddy due to previous sleet and snow that had accumulated. The work was to take place across the street from the front entrance to the plant. Four employees were in charge of hauling the rock and moving a front end loader and 40 ton truck to perform this duty. One employee was directed to stop traffic traveling north. Another employee was to stop traffic traveling south. The third employee was to drive a 40 ton truck across the roadway to the work site and the last employee was to drive a 
front end loader to the same location. With no traffic present, the employee with the 40 ton truck drove across the highway without incident. As the front end loader was crossing, the victim controlling traffic traveling northbound held up his stop sign and waved a flashlight back and forth at oncoming traffic. The driver of a 2002 red S-10 pickup truck did not see the victim in the northbound right lane and continued on, striking the victim. The driver, realizing he had just hit something, pulled to the shoulder of the road to check and saw the victim lying on the pavement. The driver of the S-10 pickup told the police that he slowed down when he saw the front end loader in the road, but the oncoming headlights of the vehicles traveling south blinded him from seeing the victim in the right hand lane. The driver also admitted that his license had a corrective lens restriction and he had a cataract in his right eye. The driver's corrective lenses were found in the center console of his vehicle indicating he was not wearing them.

One witness was 120 feet above the ground on top of a silo located northeast of the collision site. He told police that moments before the impact, he heard someone on his radio state "there is a possum with a stop sign in the roadway," and then turned to see what the comment meant. $\mathrm{He}$ observed the victim standing in the roadway and using a hand held stop sign while waving a flashlight. The witness stated he then saw the stop sign and flashlight fly up in the air and heard the impact. After immediately calling 911, he descended the silo and ran to assist with CPR.

Emergency Medical Services were contacted at 7:32 pm. The local police department was the first to arrive at 7:42 pm. The local fire department arrived at 7:51 pm, followed by EMS at 7:52 pm. Upon arrival at the scene, the local police reported the victim was lying on his back in the middle of the right-side northbound lane and could not determine if he was breathing. Advanced bleeding from his nose was noted. When the EMS arrived, they confirmed the victim was deceased. At 8:30 pm the coroner was called to the scene. The victim was pronounced dead at the scene at 9:21 pm.

The victim was wearing the basic company uniform, consisting of a gray jacket with an orange reflective stripe on each sleeve, orange stripe over the front pockets, and an orange stripe across the upper back. He was using a hand held stop sign that was not reflective, along with a small flashlight (see photo \# 3). The uniform was not American National Standards Institute (ANSI) or MUTCD approved for flagging in a $55 \mathrm{mph}$ speed area at night, nor was the stop sign ANSI approved. See photo \#1. There was no advance warning system used to warn motorists of a flagging situation ahead. Photos \#2 and \#4 are the MUTCD approved apparel and reflective stop sign that should have been used.

\section{Cause of Death}

The cause of death was multiple injuries sustained in a truck vs. pedestrian collision.

\section{$\underline{\text { Recommendations and Discussions }}$}

Recommendation No. 1: Employers should implement and enforce traffic control-related worker safety training in addition to properly setting up an MUTCD. 
Training employees on performance of traffic control activities is imperative for the safety of all involved. Policy enforcement involves adherence to MUTCD guidelines. ${ }^{1}$ Guidance includes knowledge and use of advance warning systems and recommends warning signage or warning lights to allow motorist adequate time to respond to the condition. The following should be read, understood and followed to prevent injuries or death during flagging situations: MUTCD guidelines Chapter 6C; Temporary Traffic Control Elements, Chapter 6 D: Pedestrian \& Worker Safety, 6E Flagger Control, 6F Temporary Traffic Control Zone Devices and 6 G Type of Temporary Traffic Control Zone Activities (specifically section 6G.19 for night-time).

\section{Recommendation No. 2: Employers should provide proper MUTCD reflective clothing when employees are required to perform traffic control activities.}

The MUTCD requires high visibility clothing for daytime work that meets ANSI/ISEA 107-2004 for class 2 exposure, stating that "the flagger's vest, shirt or jacket shall be either orange, yellow, yellow-green, or a fluorescent version of these colors. ${ }^{2}$ For night time work, similar garments shall be retro reflective meeting ANSI/ISEA 107-2004 for class 3 exposure. The retro reflective material shall be either orange, yellow, white, silver, yellow-green or a fluorescent version of these colors, and shall be visible at a minimum distance of 1,000 feet. The retro reflective clothing shall be designed to clearly identify the wearer as a person."

All traffic control devices such as flags and stop signs, when used at night, shall be retro reflective as well. Additionally, all high visibility clothing should be replaced when it becomes worn, torn, or defective.

\section{Recommendation No. 3: Employers should avoid assigning traffic control activities after dark.}

Traffic control activities after dark increase employee exposure to environmental hazards. Employers should avoid assigning these tasks after dark to reduce risk but, if necessary, the use of portable light plants may increase flagger visibility. ${ }^{3}$

Recommendation No. 4: When corrective lenses are prescribed and an operator's license is restricted to driving with corrective lenses, motorists must wear the corrective lenses while driving.

Corrective lenses are prescribed to ensure clarity of vision. If an operator's license is restricted to wearing corrective lenses, the driver must wear them while driving. Not only does this prevent collisions, but failure to comply is a citable offense if pulled over by an officer. The driver of this vehicle was issued a citation. 
Keywords

Flaggers

Class III clothing

High Visibility Clothing

Night time flagging

\section{References:}

${ }^{1}$ Federal Highway Administration. Manual on Uniform Traffic Control Devices. 2009 ed. Baton Rouge: Claitor's Law Books and Publishing. 2010. Print.

2“"Regulation and Policy". Work Zone Mobility and Safety Program. Federal Highway Administration. n.d. Web. 28 September 2014.

${ }^{3}$ University of Kentucky, Kentucky Transportation Center. Guidelines for Traffic Control in Work Zones, 2008. PDF.

Case Report SURVEY: https://www.surveymonkey.com/s/13KY066

\section{Acknowledgements}

The Kentucky FACE program would like to thank the Kentucky Labor Cabinet and Kentucky OSHA, the Sheriff's department and the Coroner for their assistance with this report.

The Kentucky Fatality Assessment \& Control Evaluation Program (FACE) is funded by grant 2U60OH008483-10 from the Centers for Disease Control and Prevention and the National Institute for Occupational Safety and Health. The purpose of FACE is to aid in the research and prevention of occupational fatalities by evaluating events leading to, during, and after a work related fatality. Recommendations are made to help employers and employees have a safer work environment. For more information about FACE and KIPRC, please visit our website: www.kiprc.uky.edu 


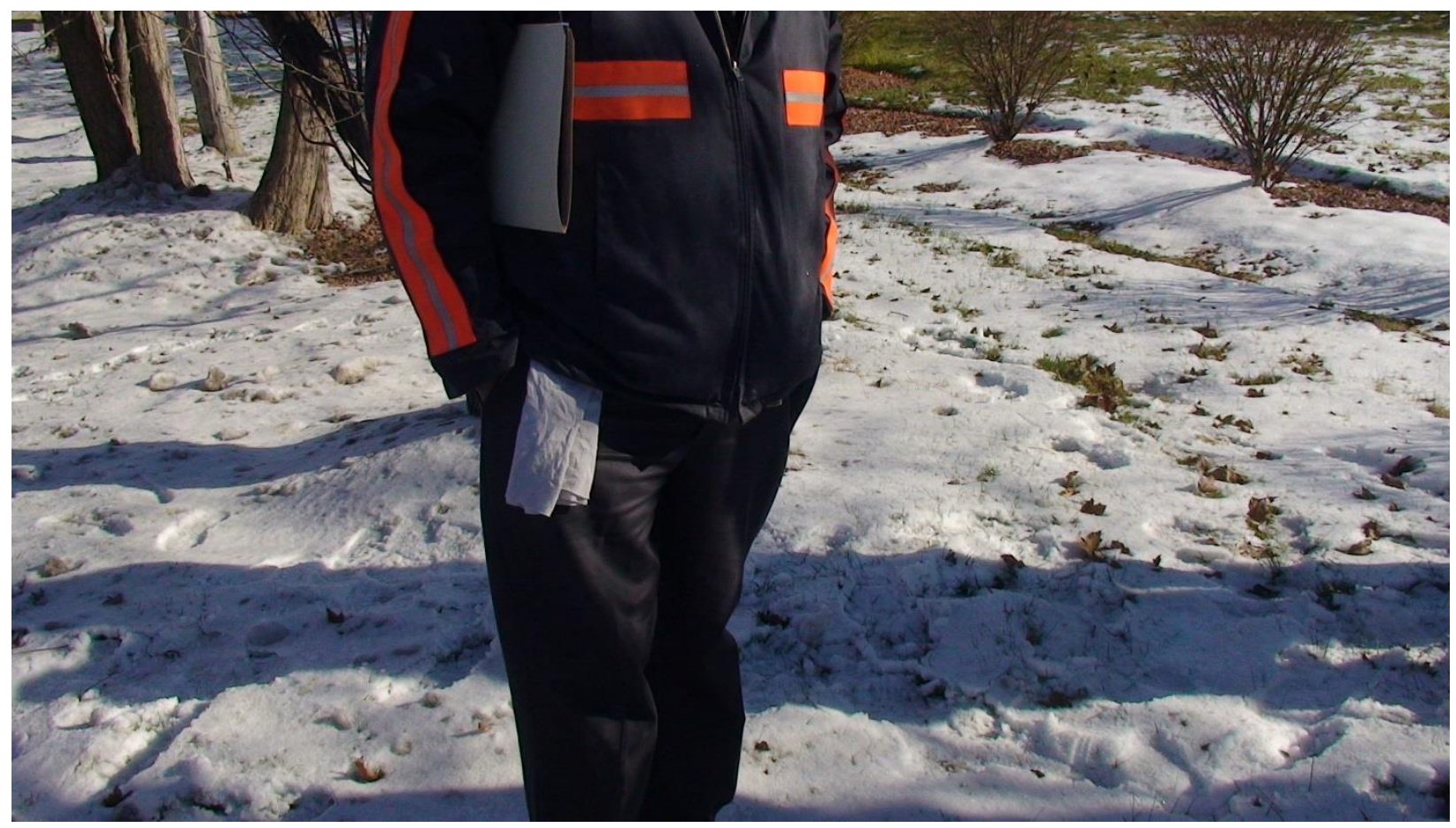

Photo \#1 Clothing the victim was wearing.

Photograph courtesy of KY OSHA 

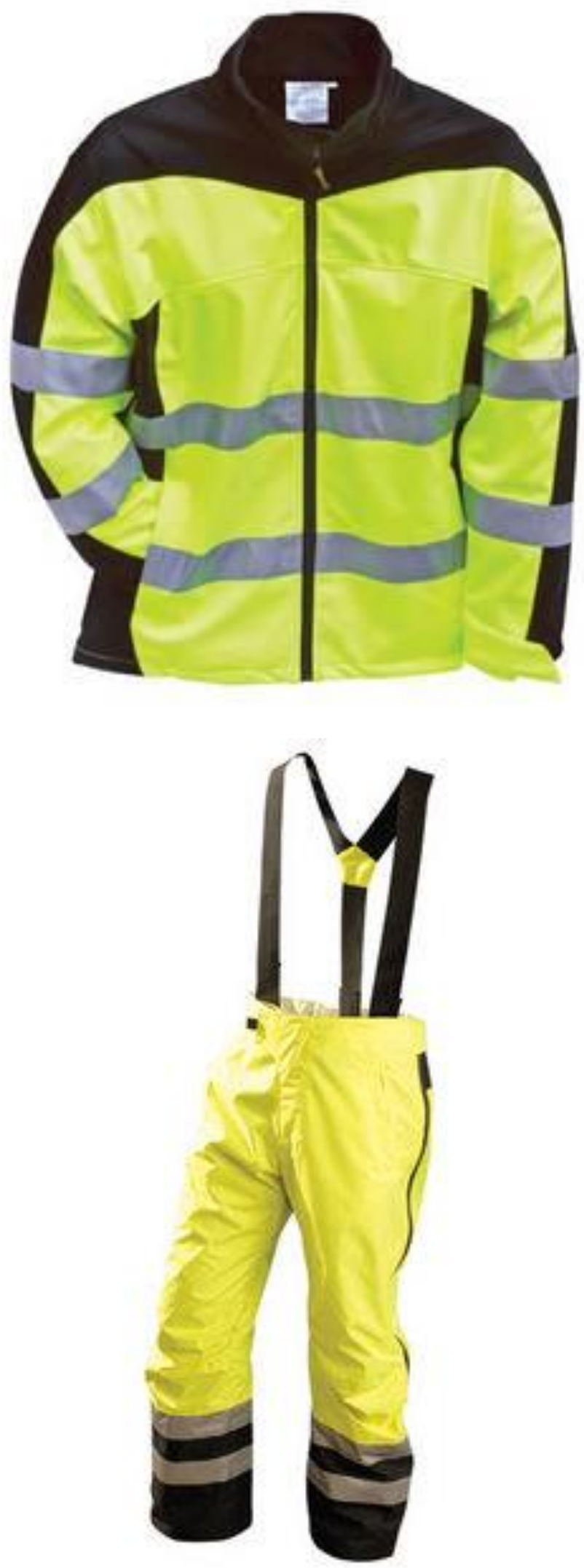

Photo \#2 MUTCD approved reflective clothing for night time flagging 


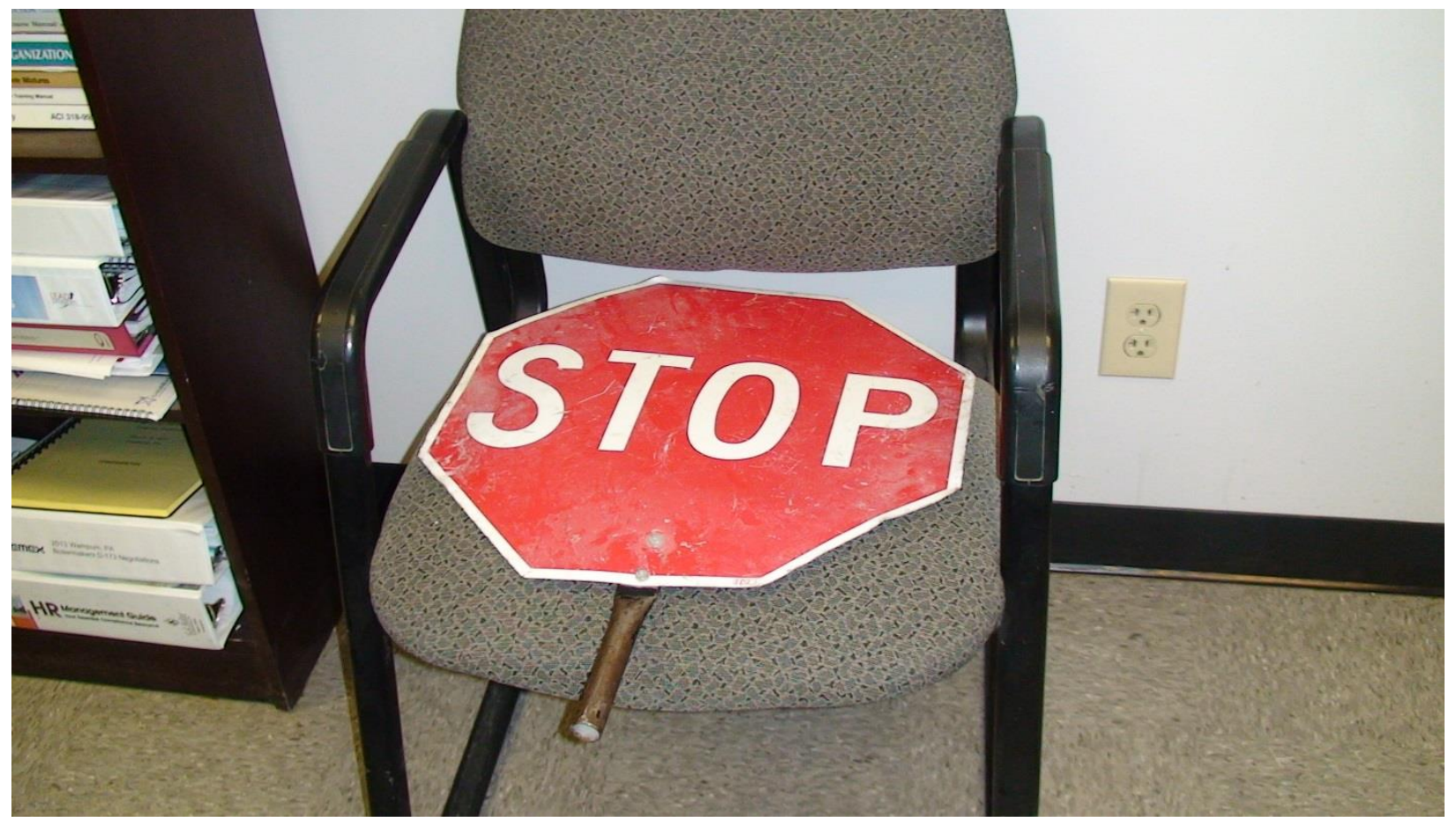

Photo \#3 Stop sign the victim was using.

Photograph courtesy of KY OSHA

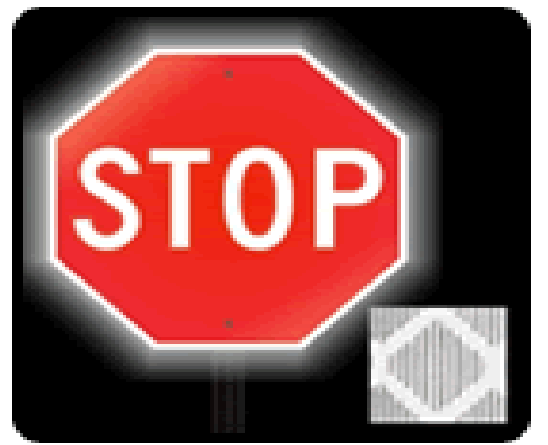

Photo \#4 Reflective MUTCD approved sign 


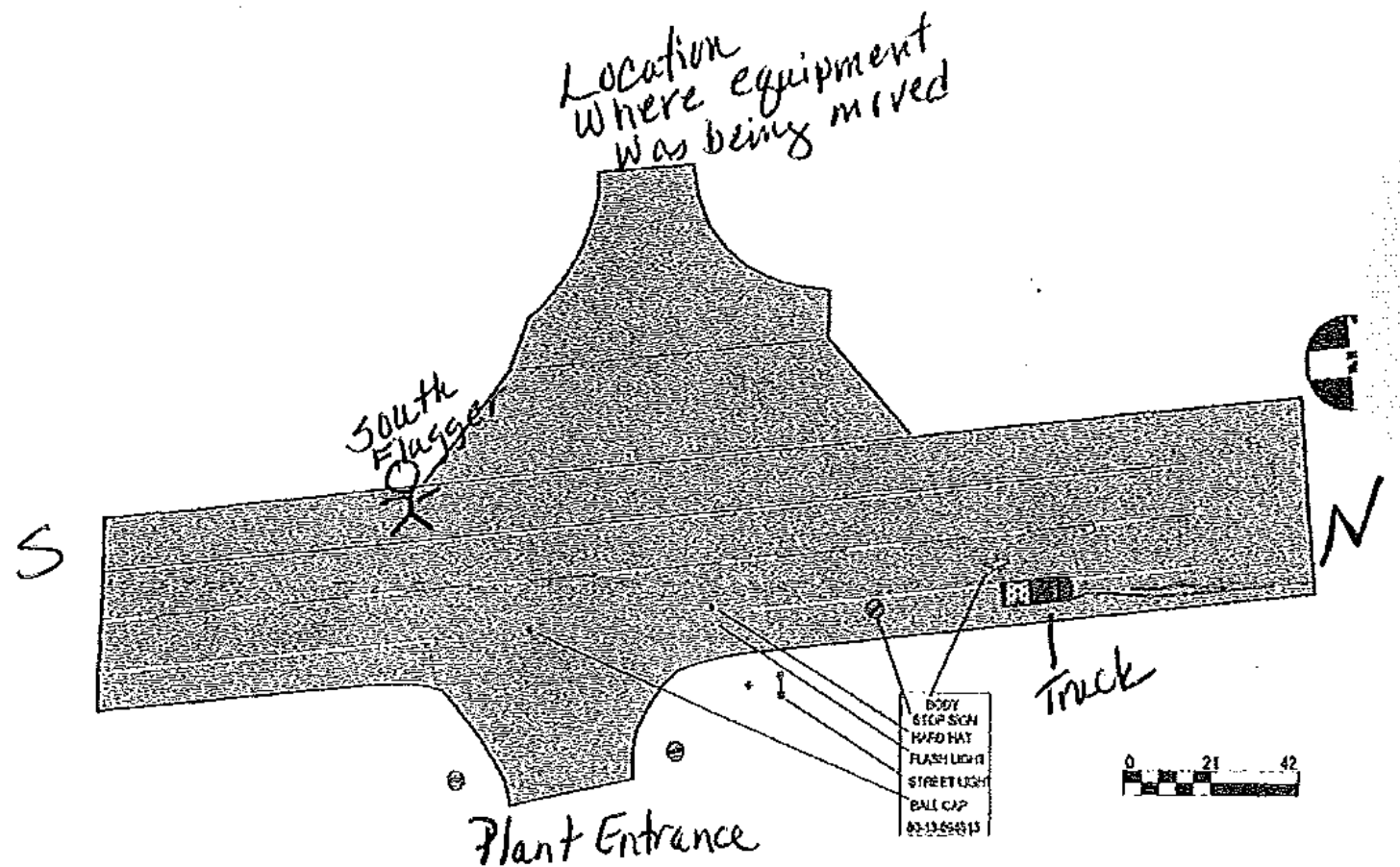

Photo \#5 Graphic reconstruction of incident site. Diagram courtesy of KY OSHA. 